\title{
Preperitoneal Pelvic Packing
}

\author{
Dong Hun Kim, Ye Rim Chang \\ Department of Surgery, Trauma Center, Dankook University Hospital, Cheonan, Korea
}

Preperitoneal pelvic packing (PPP), a component of damage control, may be a feasible tool in the management of exsanguinating pelvic fractures. Pelvic packing within the abdominal cavity is an ineffective tamponade to the pelvis. However, when surgically packing the retroperitoneal pelvic space, the hemorrhage is likely to be controlled by increasing tamponade within the retroperitoneal space. We demonstrate the method of PPP in a video clip.

(Trauma Image Proced 2017(1):42-43)

Key Words: Pelvic Bones; Fractures, Bone; Surgical Procedures, Operative; Retroperitoneal Space

\section{CASE 1}

A 24-year-old woman suffered a complex pelvic fracture with hemodynamic instability after blunt trauma. The injury severity score was 24.The patient underwent blood transfusion and preperitoneal pelvic packing (PPP) on both sides of the true pelvis via a lower midline incision in the emergency room (Video 1). The bleeding was controlled, and the gauze was removed 28 hours after PPP.

\section{CASE 2}

The right abdomen of a 66-year-old man was run over by a roll of steel pipes. Systolic blood pressure was 90 to $100 \mathrm{mmHg}$ despite initial transfusion of 2 units of packed red blood cells. Physical examination of the abdomen showed a peritoneal irritation sign. Abdominal computed tomography showed an unstable pelvic fracture with a hematoma of the right pelvis. Subse- quently, he underwent PPP via a Pfannenstiel incision and primary repair of the small bowel (ileum) via a separate midline incision (Video 2). The gauze was removed 19 hours after PPP.

\section{DISCUSSION}

The technique of PPP is described briefly. An approximately $8 \mathrm{~cm}$ lower midline incision or a low transverse incision (Pfannenstiel) is used from the umbilicus to the symphysis. The linea alba is incised and the peritoneum is left intact. During blunt dissection through the preperitoneal space from the posterior aspect of the pubic symphysis to the true pelvis on each side of the bladder, the pelvic hematoma is encountered and should be eliminated. The inner aspect of the quadrilateral plate is exposed by palpating the pelvic brim, and so the anterior aspect of the sacroiliac joint is reached. A minimum of three large radiopaque surgical pads or Quickclot Traumapads (Z-Medica Corporation,

Received: February 12, 2017 Revised: February 22, 2017 Accepted: March 1, 2017

Correspondence to: Dong Hun Kim, Department of Surgery, Trauma Center, Dankook University Hospital, 201 Manghyang-ro, Dongnam-gu, Cheonan 31116, Republic of Korea

Tel: 82-41-550-7661, Fax: 82-41-550-0039, E-mail: saint7331@gmail.com

Copyright (c) 2017 Korean Association for Research, Procedures and Education on Trauma. All rights reserved.

@This is an open-access article distributed under the terms of the Creative Commons Attribution Non-Commercial License (http://creativecommons.org/ licenses/by-nc/4.0) which permits unrestricted noncommercial use, distribution, and reproduction in any medium, provided the original work is properly cited 
Wallingford, CT, USA) are placed into the true pelvis below the pelvic brim. Pads are placed sequentially from the anterior aspect of the sacroiliac joint to the retropubic area through the inner aspect of the quadrilateral plate. The fascia is closed with a running PDS suture and the skin with a running nylon suture or staples. In patients requiring laparotomy for intraabdominal trauma, the two incisions should be separated for optimal tamponade of PPP $(1,2)$

\section{Conflict of Interest Statement}

No potential conflict of interest relevant to this article was reported.

\section{REFERENCES}

1. Burlew CC, Moore EE, Smith WR, Johnson JL, Biffl WL, Barnett $\mathrm{CC}$, et al. Preperitoneal pelvic packing/external fixation with secondary angioembolization: optimal care for life-threatening hemorrhage from unstable pelvic fractures. Journal of the American College of Surgeons. 2011;212(4): 628-35.

2. Tötterman A, Madsen JE, Skaga NO, Røise O. Extraperitoneal pelvic packing: a salvage procedure to control massive traumatic pelvic hemorrhage. Journal of Trauma and Acute Care Surgery. 2007;62(4):843-52.

\section{Video Legend}

Video 1. A video recording in the emergency room shows PPP on each side of thebladder via a midline incision with the patient under local anesthesia.

Video 2. A video recording in the operating room shows ipsilateral PPP via a low transverse incision followed by primary repair for small bowel perforation via a midline incision. 